\title{
The Teaching Reform of Ideological and Political Courses from the Perspective of Core Literacy
}

\author{
Yang jianyun
}

Shanxi international business college, Xi'an,Shaanxi 712046,China

*Corresponding author. Email:5386682444@qq.com

\begin{abstract}
In order to better implement the spirit of Xi Jinping's "3.18" speech, and in view of the current unsatisfactory situation of ideological and political course teaching in colleges and universities, the teaching reform of ideological and political theory course in colleges and universities should focus on the formation of students' core qualities and renew the educational concept, to unify ideological understanding, strengthen team building, reconstruct course system, select teaching content, innovate teaching method and flexible evaluation method, so as to improve the effectiveness of ideological and political teaching.
\end{abstract}

Keywords: core literacy, ideological and political education, teaching reform

\section{核心素养神域下的高校思政课教学改革}

陕西国际商贸学院, 西安, 陕西, 中国

杨建云 通讯作者: 386682444@qq.com

摘要:

为更好落实习近平 “ 3.18 ” 讲话精神，针对当前高校思政课教学不理想的现状，高校思想政治理论课 课教学改革应当围绕学生核心素养的形成, 更新教育理念, 统一思想认识, 加强团队建设, 重构课程 体系, 精选教学内容, 创新教学方式, 灵活评价方式, 从而提高思政课教学的实效性。

关键词: 核心素养; 思政课; 教学改革

\section{1. 引言}

习近平总书记在 “3.18” 讲话中强调, 办好学校思 政课, 事关中国特色社会主义事业后继有人, 是培养一 代又一代社会主义建设者和接班人的重要保障。在这个 问题上，必须提高政治站位、深化思想认识，必须旗帜 鲜明、毫不含糊, 理直气壮开好思政课, 把立德树人的 根本任务真正落实到位。 ${ }^{[}$] 但我们也看到由于对思政课 实际重视度不够, 课堂教学效果欠佳, 实践教学流于形 式, 学科评价方式单一等问题, 影响到了思政课教学目 标及高校学生培养目标的实现。这里我们从核心素养的 角度谈谈当前思政课教学改革问题。

\section{2. 重要概念解读}

清楚核心素养关键问题, 更新教育理念, 统一思想认 识。从学校领导到思政课教师都要看到当前高等教育改
革发展的趋势, 清楚新世纪我们要培养什么人, 怎么培 养人这个问题, 以学生核心素养的培育为做为终级目标 高校立身之本在于立德树人。核心素养视域下进行思政 课教学改革必须弄清楚以下几个概念:

\section{1 核心素养}

核心素养是所有学生应具有的最关键、最必要的基 础素养, 是知识、能力和态度等的综合表现。核心素养 兼具个人价值和社会价值, 具有发展连续性和阶段性, 是可以通过接受教育来形成和发展的。

\section{2 学生发展核心素养}

学生发展核心素养, 主要指学生应具备的, 能够适 应终身发展和社会发展需要的必备品格和关键能力。经 研究, 普遍认为, 中国学生发展核心素养的框架体系以 “全面发展的人”为核心，为文化基础、自主发展、社 


\section{4. 核心素养视域下思政课教学改革的路径}

会学习、健康生活、责任担当、实践创新六大素养。[2]

\section{3 学科核心素养}

学科素养是核心素养在特定学科(或学习领域)的 表现, 是学生学习一门学科课程(或特定学习领域)之后 所形成的、具有学科特点的关键成就, 是学科育人价值 的集中体现。

\section{4 思政课核心素养}

思政课核心素养是核心素养在思政课的体现, 思政 课核心素养的建构也是知识、方法、能力与情感、态度 和价值观的整合。具体来说，思政课核心素养包括思想 政治基础理论常识; 理论联系实际的学习方法和辩证思 维方法, 参与社会生活的实践能力、价值判断和选择的 能力、社会观察与分析问题的能力; 正确的政治方向、 正确思想观念、良好道德品质等。通过培养思政课核心 素养, 为学生终身发展奠定思想品德和思想政治素养基 础。

\section{3. 高校思政课教学改革的必要性}

\section{1 是更好贯彻落实习近平 “3.18” 讲话精神 的必然要求。}

习近平在今年的 “ 3.18 ” 讲话中提出推动思想政治 理论课改革创新, 要坚持八个 “相统一”, 提出传导主流 意识形态, 要直面各种错误观点和思潮; 加大对学生的 认知规律和接受特点的研究, 发挥学生主体性作用; 注 重启发性教育等。所以办好思政课, 只有遵循八个 “相 统一”, 契合学生发展实际, 遵循人才成长教育规律特点, 才能开好思政课。[3]

\section{2 是改变当前高校思想政治理论课教学现状 的重要路径。}

围绕习近平总书记的 “ 3.18 ” 讲话及相关文件要求, 各高校都相继开展了思政课改革创新的研讨和实践活动, 但总体来说, 效果还不理想。主要表现在: 教学目标抽象 化, 过于理想, 且表达不够具体; 教学内容标准化, 过于 重视政治性和知识性, 忽视了情感、态度和价值观的教育; 教学方法机械化, 灌输式依然占主导地位; 考核方式单一, 形式化严重。以上等问题的存在, 严重影响到思政课的教 学效果。

\section{1 在学校统一领导下, 以思政课教学科研机 构为主体，组建团队，把高校思政课课程与核 心素养进行对接。}

各个学校由于定位、专业、地域等的不同, 对本校 学生发展核心素养的要求在中国学生核心素养的框架体 系下会有所侧重, 或增加, 所以首先学校要根据学校实 际、学生特点, 根据学生培养目标和要求, 制订出本校 学生发展核心素养。然后由思想政治理论课教学科研机 构以教研室为团队主体, 邀请学校领导、校内外专家学 者, 吸引学生处、团委、辅导员等校内各部门老师参加, 形成专门研究团队, 对思想政治理论课核心素养进行研 究。以 “马克思主义基本原理概论” (以下简称 “原理” ) 为例, 可以以 “原理” 教研室的所有人员及其他院校的 兼职老师为团队主体, 然后邀请学校书记、二级学院书 记、团委书记、辅导员、学生处领导参与, 最后邀请校 外专家对研究结果进行指导。在研究过程中, 首先要认 真学习中国学生发展核心素养、思政学科核心素养和本 校学生发展核心素养的内容和要求; 其次结合《原理》 课程的具体性质和内容。“马克思主义基本原理概论”， 研究在 “原理” 课的教学中, 主要培养学生哪些核心素 养, 通过哪些内容哪些方式培养, 并据此制订出本课程 新的课程标准。课程标准内容至少应该包括课程性质目 标、教学内容和基本要求、考核方式、实践方式等, 其 中教学目的和要求要突出对学生核心素养的培养。

\section{2 打造思政课教学新课堂, 提升学生核心素} 养。

（1）根据课程核心素养及新课程标准，对课程内容 进行有效取舍, 突出学生核心素养的养成。仍旧以 “马 克思主义基本原理概论” 为例, 在对教学内容进行取舍 时, 首先要了解中学政治课的教学内容和要求, 对中学 已经接触过的内容, 基本概念部分可一带而过, 由学生 自己看, 但对一些重点内容可在原来学习的基础上进行 扩展和加强。其次是结合其他思想政治理论课的课程内 容和要求, 对一些重复部分的内容进行科学处理, 既不 影响课程内容的整体性, 又不会因为重复浪费时间, 也 影响教学效果。最后是根据课程核心素养要求和新课程 标准, 对内容进行取舍。核心素养指向品格和关键能力, 但离开知识这一抓手, 品格和关键能力的培养将成为空 中楼阁。思想政治理论课除了 “形势与政策” 课外, 其 他课程都自成一个完整的体系, 内容很多, 但课时有限, 如果按照教材内容和传统教学注重知识传授, 学生就无 法对问题进行深入思考, 就无法养成良好品格, 提升学 生关键能力。所以这就要求教师必须精选知识, 剔除不 必要的繁杂的知识, 把教材体系转换为教学体系, 在有 限的课时里, 给留足学生思考交流的时间和思维空间, 
的平时成绩。对于实践成绩, 除了根据学生的课内实践 表现及社会实践调研论文给予相应成绩外, 学生在参加 其他活动获得的奖项也可以适当给予一定成绩, 以示激 励。第二, 笔试成绩可以增加期末考核或单元考核, 强 调对学生的学习过程的考核。鉴于时间关系, 每个学期 1-2 次即可。考核方式采取开卷方式, 在教学过程当中抽 一个课时当堂进行测验, 也可以布置下去, 由学生课下 完成, 可以是纸质的, 也可给老师发 E-mail。当然也可 以把某次课堂讨论的结果做为其中的一次考核。可以针 对所学内容, 选取社会热点、焦点问题对学生分析问题、 解决问题的能力进行考查。期中考核成绩应该与期末考 核成绩在总成绩中占相同比例。第三，期末考试的内容 和题型设计要强调试题的开放性, 体现 “没有标准答案, 但有评价标准” 的测查新方向。这样就增加了学生回答 问题的多样性, 突出对品格和能力的考核。另外还可以 采用学生自评、互评的评价方式, 对学生进行全面考核, 力求对做到考核结果客观、全面。

(3) 考核主体多元化。结合上面多样化的考核方式, 所以对学生的考核主体除了任课老师外, 包括辅导员、 班委、辅导员和学生自己都可以是评价主体, 参与其中。

当然这些教学改革还离不开学校有力的支持和保 障, 比如制度保障、人力保障、经费支持、科研奖励 等, 只有这样才能形成发展学生核心素养的长效机制, 核心素养视域下的思政课教学改革才能取得实效。

\section{致谢}

的特殊性, 单一的考核方式并不能真实地反映教学成效, 所以要构建以学生核心素养为中心的考核体系, 科学评 价思政课的教学实效性。

（1）考核内容要全面。思政课考核注重的是学生思 想道德、政治素质的评价, 是对学生情感、态度与价值 观方面的反映。所以考核内容除了基础理论, 更要突出 学生运用所学知识分析实际问题的能力的考核, ; 除了 将学生在思政课上的纪律、参与课堂教学的态度、持有 的观点、能力的发展等方面纳入考核外, 还要对学生日 常的思想、道德、法纪等行为进行考核, 这样才能对学 生做出科学准确的评价, 才能对学生的行为起到正确的 引导作用; 除了对学生的作业、课内实践情况进行考核 外, 还要将学生参加各种社会实践活动的表现进行考核, 对学生进行社会实践能力的考核。

（2）考核方式要多样。在考核方式上要改变以往重 学习结果考核轻学习过程考核的问题, 建立发展性评价 模式, 注重对学生学习过程的考核。一般高校思政课的 考核成绩包括平时成绩和期末成绩两部分, 其中平时成 绩就是对学生的过程考核。第一, 平时成绩的考核方式 除了考勤、作业外, 课堂表现部分应该除了纪律, 应该 重要强调学生参与教学环节的程度, 发言的数量与质量。 再者, 可以采取学生自评、互评的方式, 或者与班委、 辅导员合作, 对学生的日常表现进行考核, 也计入学生
本文为陕西国际商贸学院 2019 年度教育教学改革项 目《新时代思政课金课建设的生活化转向及其路径研究》 （项目编号：JG201915）的阶段性成果之一。

\section{REFERENCES}

[1]Xi jinping. Casting souls and educating people with the thought on socialism with Chinese characteristics for a new era, implementing the party's education policy, and carrying out the fundamental task of establishing morality and cultivating people [M]. People's Daily, 2019-03-19: A01.

[2] Lin chongde. Research on the core literacy of student development in the 21st century [M]. Beijing: Beijing normal university press, 2016.

[3]Zhang Ruifu, Zhang Gankun. On the gradual progress of ideological and political course and its scientific actual effect. Shandong Education (higher education), 2019(6) .

[4]Zhu Qiaoying. Research on three-dimensional practical teaching mode to promote students sense of attainment in ideological and political course J. Journal of Shandong Youth Vocational and Technical College, 2018(9) . 